\title{
Microplanning and Language Policy in Morocco
}

\author{
Aziz Moummou \\ Laboratory of Language, Literature and Translation, Faculty of Humanities and Social Sciences, \\ Mohammedia \\ University Hassan II, Morocco
}

\begin{abstract}
Language policy and planning (LPP) has undergone an epistemological turn. Early LPP works approached linguistic diversity as a problem; especially for the newly independent states, but in today's globalized world, multilingualism is the norm. A major issue that characterizes contemporary LPP in Morocco and needs further investigation is the interaction between macropolicies and local practices. Most top down language policies face resistance from speech communities. The purpose of this paper is to illuminate the role of micro-planning and local agents in implementing a workable language policy. The aim is to reduce the gap between LPP research and local practices by using an ethnographic approach. Ruiz orientational model and Spolsky's management theory provide a rich theoretical framework. Micro-planning can translate central policies into local practices.
\end{abstract}

Keywords: microplanning, macro policy, multilingualism, LPP theory, Management theory, Orientation model, local practices

\section{Introduction}

Language Policy and Planning (LPP) becomes a solid legacy in contemporary applied linguistics. It is apparent that LPP succeeded to maneuver the shift from being an art (Haugen,1966) into being a full-fledged science of its own theory (Fishman,1974). In his foundational study of Norwegian sociolinguistic situation, Haugen E. compared language planning to a work of prophecy. He posited that:

Language planning is therefore still more of an art than a science. Like politics, of which it is a part, it is the art of the possible. The language planner must have some of the 
equipment of the prophet or the soothsayer: to foresee the wave of the future and ride it to its goal. (Haugen E. 1966, P.26)

This definition seems logical in its historical context, as LPP in its early developmental stages did not have a clear theoretical framework. Still, this comparison alluded to fundamental elements for a future theory: a "deliberate effort" and "a goal-oriented" planning.

Ford Foundation, a US philanthropic organization initiated a new episode in the history of LPP. In an international research project, Ford funded eminent LPP scholars (Fishman J. Ferguson and Das Gupta, respectively) to study language situation in newly independent states of Africa and South east Asia. The project is referential in the field and provides insights on early language planning practices. One could confidently posit that Ford project marked the advent of language planning and policy as an independent scientific field. This paper purports to overview the evolution of the field and situate LPP in its state-of-the-art context. Unlike early LPP ideology, this paper advocates the power of local agents and the primacy of micro planning in building a solid language policy. It attempts to answer the following questions:

* How can local practices and macro policy interact?

* What mechanisms can reconcile the role of local agents in macro-policy?

- How can microplanning improve both policy and practices?

\section{Background}

Scholars in language policy and planning (LPP) often associate the term with Haugen E. in a paper given at the American Anthropological Association in November 1958. Yet, the author himself acknowledged that "Uriel Weinreich was first to use the term as the title of a seminar given at Columbia University in 1957 (Haugen E. 1966,p, 355)".'Yet,Haugen Einar is undoubtedly a pioneer linguist to provide a primary definition of language planning. He posited that language planning is:

the normative work of language academies and committees, all forms of what is commonly known as language cultivation (Germ. Sprachpflege, Dan. sprogrfigt, Swed. spräkvärd), and all proposals for language reform or standardization. (Haugen (1969:287) as cited in Fishman, 1974, p.105) 
This definition reflects the ideological orientation of LPP in early 1960s. The academia in that era approached language as a problem of multilingual speech communities, therefore the primary task of language planning was to establish a linguistic uniformity (monolingualism). Einar Haugen considered language problems to stem from two basic constituents, form and function. Henceforth he proposed a model where most language solutions were either theoretical frameworks to improve language structure or practical processes to elaborate its functions. Haugen E. (1966) explained that :

The initiation in the case of linguistic form will be called the selection of a norm, while the implementation will be referred to as the codification of form. In the case of linguistic function, the initiation will here be known as the elaboration of function, while the implementation will be called acceptance by the community. (p, 18)

We suggest the following table to illustrate Haugen's model:

\begin{tabular}{|l|l|l|}
\cline { 2 - 3 } & Form & Function \\
\hline Initiation & Selection of norm & Elaboration of function \\
\hline Implementation & Codification of norm & Acceptance by the users \\
\hline
\end{tabular}

Table 1. Haugen E. model for language planning

In the present time, Haugen's model persists in LPP studies. It still influences language policy in many parts of the world, especially in African polities. The notion of nationalism seems to compete intensely with nationism, the margins with central governments and uniformity with diversity. This paper may sound impressionistic if it claims that most newly independent states adopt a language policy of the colonizer. In Morocco, local and global factors exert a powerful pressure on national language policy. We can still observe that French is omnipresent. On the local level, the 2011 constitution has declared standard Arabic and Amazigh as the official languages in Morocco. It ended up sixty years of Arabization as being the policy of solidarity and regional identity. This declaration reflects both political and societal interests. On the political level, the Arab spring brought into surface the issue of human rights and therefore empowered the Amazigh movement demands for equity in linguistic rights. On a societal level, there was a concern that the ethnic marginalization will cause racial confrontations as was the case in the neighboring Algeria. However, Amazigh language policy is not without its defaults. Haugen's model informed Amazigh officialization and unified three varieties under the umbrella 
of Tifinagh script and Amazigh language. The uniformity engendered a diglossic situation where two languages live side by side with their varieties (standard Arabic with Moroccan Darija and Amazigh with Tashelhit, Tarefit and Tamazight). On a global scale, Morocco's economic interests shaped its recent language policy. The ministry of education announced that French will regain its position as medium of instruction in scientific and technical subjects, it also hastened to declare a new system for the Moroccan university (Bachelor system) where proficiency in foreign languages (mainly French and English) is mandatory. The beforementioned decisions show that language policy in Morocco whether overt or implicit moves away from the classical theory of language planning (Haugen,1966) that deals with multilingualism as a problem, and embraces new orientations in language planning, namely language as a right and language as a resource (Ruiz ,1984). The call for a unique national identity, where monolingualism is ideal, is losing ground for linguistic diversity. Besides, multilingualism is not seen as a factor of divisiveness anymore, but rather as a display of cultural coexistence.

This paper views Ruiz orientation model as paradigmatic for a contemporary research. Unlike many language planners (Neustupny, 1970; Rubin and Shuy, 1973; Fishman, 1975) who adhered to Haugen's model and considered language planning a problem-solving process; Ruiz contemplates that language planners should treat language from different perspectives/orientations. He added "Orientation, as it is used here, refers to a complex of dispositions toward language and its role, and toward languages and their role in society. "(Ruiz, 1984, p.16). In other words, language planners must consider attitudes (often unconscious) of speech communities towards certain languages and the types of functions to be allotted to each language. This theorization started an epistemological shift in language planning as it brings language users to the epic center of planning. This shift paved the way to contemporary approaches such as the critical approach and domain approach and Spolsky's management theory. Critical approach highlights the effectiveness of micro-language planning and the interests of language users. Domain approach initiated by Fishman advocates the primacy of contextualization in language choice. Yet, Spolsky’s language management approach brings a whole new line of thought to the field. For B. Spolsky, there are three fundamental components in language policy design: Language beliefs/ideology, language current practices and management (see the discussion below). To argue for this paper's prior claim: micro-planning 
can implement a workable language policy, there are many reasons to advocate language management theory and the critical model.

The critical model pushed LPP into a different direction. It untangled the field from problem solving attitude that characterized the research for decades, Besides, it criticized the dominant narrative where most language policies serve the interests of an elite community. Tollefson (2006) argued that a critical approach has three major goals:

(1) it is critical of traditional apolitical LPP approaches and instead "acknowledges that policies often create and sustain various forms of social inequality, and that policymakers usually promote the interests of dominant social groups"

(2) it seeks to develop more democratic policies which reduce inequality and promote the maintenance of minority languages; and

(3) it is influenced by critical theory. (p. 42 as cited in Johnson D.C.and Ricento T. 2013, p. 11)

To reduce social inequality, this paper suggests micro-planning. Microplanning posits that the agency of local policy makers will secure an effective implementation of language policy. It is time to reverse the relationship between the center and the margins. The classical paradigm that produces policies at central governments and imposes them on the margins is ineffective. The question now is how can micro-level interactions influence macro-level policy? The answer is possibly inherent in language management model. This theory relies on the individual speaker to introduce a policy of language planning and advocates the pressure of local practices on nation state policy. Spolsky has continuously criticized central government policies He argued that macro policies overlook the different layers in policy design and enumerated unsuccessful experiences whether in Ireland, or the newly independent states of Africa. He introduced management theory as a model to produce a workable language policy. There are three basic elements in this theory as Spolsky (2009) posited, “A second assumption, presented in my earlier book (Spolsky 2004), is that language policy has three interrelated but independently describable components-practice, beliefs, and management" (p.04).

Language practice represents the linguistic choices of speech community, what people do with language. Respectively, language belief and ideology reflect users' attitudes towards the language, be it positive or negative. The two last components are very salient for the development of this paper's claim. The first is management and the second is self-management. 
Spolsky explained that "The third component of policy is language management, the explicit and observable effort by someone or some group that has or claims authority over the participants in the domain to modify their practices or beliefs" (2009, p.04). in this component, there is a balance between the top down and bottom up processes of language planning. It is believed that in language management the responsibility is shared between central government policy makers and local agents (teachers, students, university administrators). Spolsky differentiated between managers with power and advocates without power (2018). Obviously central government policy makers are managers with power but how about students and teachers, are they managers or advocates?

Spolsky added another important component in his revised theory (spolsky,2018) and named it a self-management component. Bernard Spolsky argues that "It seems now almost trivially obvious to include in language management theory the attempt of speakers to modify their own linguistic proficiency and repertoire (2018, par.11)". It is apparent nowadays that some languages (English, Mandarin) attract more users. At university, English is the first language students and professors want to improve, since it is the language of research and wider communication. In Morocco, French remains a powerful foreign language but with limited positive attitude among university students. This paper advocates the empowerment of selfmanagement and considers it a deliberate effort to improve one's proficiency in a language.

The voluntary feature in self-management is what this paper relies on to produce a language policy for university students. We propose a language policy that aims different layers of micro-planning: teachers and students. For the latter, a micro-planning policy will celebrate the autonomy of learners, reinforce ownership of learning process and nurture leadership skills. For the former, this policy will make teachers principal mediators between a macro-level, topdown policy and local practices. In Morocco, there seem no better opportunity for such a policy than the newly adopted tertiary system (Baccalaureaus).

To conclude, this paper considers Haugen's model a signpost in the history of classical theory that may not adequately answer the contemporary language practices. However, the classical theory is still a tradition in some polities. Therefore, the model proposed by Ruiz (1984) is inclusive as it expands orientations in LPP beyond language as a problem (classical theory) to language as rights and as resource. For today's society, language management theory is a workable model for producing a language policy. In the same vein, it is time to reduce space for 
macro-level planning to a more bottom up, micro-planning as it promises richer linguistic practices. The methodological framework in language planning is directly influenced by ideological, political and societal factors. This paper is not an exception. To argue for a bottom up policy is not apolitical. However, our aim is to advance research in language policy from a general theory of sociolinguistics.

\section{Methodology}

The would-be researcher in language planning and policy is confronted with an array of methodological tools. Therefore, an LPP research must carefully and clearly declare its basic claims and the underlying ideology. This paper believes that micro-planning as a bottom up policy will produce effective practices on the ground and reduce social inequalities. In other words, the aim is twofold. First, nurture effective practices in teaching English for university students. Second, narrow the linguistic gap of the underprivileged students (some students enroll in paid language centers to improve their proficiency). This qualitative research intends to understand the characteristics of ELT practices at university and how it can help designing a language policy. To confirm this claim, the study will employ an ethnographic approach. Since early 2000, there has been a massive turn to ethnographic methods as it enables researchers to study language practices on locales as schools, universities and language institutions. Johnson D.C. and Recento argue that "The ethnography of language policy has been proposed as a method that combines a focus on structure and agency, the macro and the micro, policy and practice" (2013, p.16). The ethnographic approach promises to explore local differences in context. In this regard, LPP has been recently focused on producing specific results for specific contexts. However, some polities continue to overlook this fundamental variable and adopt policies that were meant for a different context. Ethnography is also a powerful methodological tool to give voice to the different actors in local language planning. In a nutshell, ethnographic research focuses on local context to overcome LPP's heterogeneous methodological approaches. Ethnography is an effective method to find out about teaching practices at university. Interviewing language teachers about the impact of policy on their practices, as well as observing some classes will give a picture about local practices.

The choice of a method among others is determined by research questions. One must craft research questions and look for the relevant methods and not manipulate the questions to 
suit the methods. This research aspires to study language policy as it translates in classrooms at all levels but particularly at tertiary education. In higher education, central governments seem to reduce its hegemony over universities' boards. Thus, it is an ideal context to observe how microplanning (classroom practices) interacts with macro policies (within a university). It is of paramount importance to choose adequate methods to collect data, especially in a pluridisciplinary field like LPP. "For LPP researchers, data collected are in the form of survey questionnaire responses, census and demographic data, linguistic databases, interview transcripts, policy documents, field notes, audio- and video-recordings, photographs, and more (Francis M. Hult \& D. Johnson, 2015, p. 15)”. Most research fail to provide sufficient data or make a link between theory and data, therefore, our orientation here is not about quantity, but how one can infer between data and theory and back?

Research in LPP remained loyal to classical paradigm (technical research) until the late 1970s. in this paradigm, variables are fundamental and constitutes the main material for interpreting social phenomena. Language planning remains a problem-solving process. It was soon criticized by the interpretive paradigm that sought to understand and explain human interactions and meanings in context. Both paradigms did not seek to change reality, they were simply obsessed in producing descriptions of the world. The study claims that the critical research paradigm provides an ethical alternative for LPP researcher seeking to change social reality and to centralize the margins.

\section{Discussion}

In this brief review of LPP theory, we understand that the field is now shifting to a new direction. It is reducing macroplanning space for a more local micro-planning. The review of classical theory and contemporary critical approach illuminates the need for an epistemological questioning that will orient future research. We will use Ruiz (1984) orientation model to frame our questions.

As mentioned earlier, Ruiz orientation model suggests that language planning is informed by three underlying perspectives or ideologies: language as right, as problem or as resources. From a rightist perspective, language users have the right to choose their language as a medium for communal life. Put differently, every speech community whether it is a major or minor ethnic group has the right to learn, communicate and improve their mother tongues. To illustrate this 
point, let us consider the Moroccan Amazigh language situation. The 2011 Moroccan constitution recognized the right of Amazigh to use their language in official proceedings and improve Amazigh acquisition as well as elaborate its forms and functions. Amazigh language planning gained momentum as it had an academy of its own, The Royal Institute of Moroccan Amazigh Culture (IRCAM). However, it has been recently declared that Moroccan languages will congregate under one single council (council of Moroccan languages and cultures).

Something that the Amazigh activists viewed as a backlash against the Amazigh movement. The orientation of language as a right might seem to focus on ethnic minorities and their linguistic rights, but it is apparent that globalization widens the concerned languages on a national, regional and international levels. Micro-planning is not the primary objective of language as a right. Central governments under pressure design a policy for minorities with a crystal-clear aim; to maintain control. If we would like to empower local groups from a language as a right perspective, we would be willing to investigate how minority language rights can be reconstructed from bottom up beyond the dictums of nationalism?

From a classical perspective, language as problem orientation may slightly contribute in developing micro planning. The main reason for that claim is that the traditional approach views linguistic diversity as a problem and uniformity as the ideal. Contrariwise, micro-planning considers multilingualism a display of solidarity and a healthy heterogeneity. Still, we can employ classical theory to promote de facto varieties to become independent and possibly de jure languages.

This paper relies heavily on language as resource orientation to improve a micro-planning model for English language policy at university. Micro-planning should aim at bringing into surface language practices in schools, universities and other educational institutions. Our focus is primarily on higher education as it requires a rich array of languages, especially a language of wider communication as English. Languages are akin to cultures in that they represent a different reality of the world. It is of paramount importance for university students to recognize 'the social value of languages competence' (Thompson, 1973). Ruiz commented on Thompson's concept and explained:

By this he seems to be saying, along with Sharp (1978:3), that language study creates an awareness in students "that their own way of thinking and living is not the only 
reasonable possible one; and that some cultures are often keenly perceptive in areas in which others are short-sighted. (Ruiz, 1984, p. 28)

Students at university are future-to- be researchers who need to take ownership of their learning. A language policy that values students as such should include some activities that nurture leadership. There are many ways we can achieve that goal. Distance learning seems a good starting point. First, in virtual educational settings, students manage their learning process and hold responsible for the outcomes. Distance learning can reduce the growing educational inequalities, especially in the south (underdeveloped educational systems). Most renown educational institutions offer free online courses for the global audience. Finally, distance learning is an ideal platform for differentiation pedagogy. As evidence shows, human beings possess multiple intelligences, therefore they have different styles of learning. In a virtual setting, students could choose from the array of available resources that meet their learning style. Another creative micro-policy should foster peer learning. In the example of language learning, students from language departments will be invited to voluntarily run language peers. The creativity of language peers will largely depend on the autonomy granted by teachers and the universities' board members.

Micro-planning also aspires to empower teachers as active local agents. The failure of consecutive language policies in many parts of the world is a result of resistance from language users to macro-planning, as Hornberger and Johnson argue," The texts are nothing without the human agents who act as interpretive conduits between the language policy levels (or layers of the LPP onion)" (Hornberger \& Johnson, 2007, p.528) . Therefore, a workable language policy will require a participatory approach. Respectively, the first layer of an ideal policy will start with teachers. Teachers are not candid recipients of top down decisions; they are transformative agents. They play a decisive role in translating language policies as they control the final stage,i.e. implementation. Henceforth, micro-planning values teachers as carriers of change. It encourages them to participate in research not as the researched but as insider researchers through an ethnographic approach.

Micro-planning promises to benefit from the growing momentum of tertiary education. In most polities, there is an ongoing decentralization process. Universities have independent status in terms of budgetary planning, research centers as well as academia. The study proposes to 
encourage universities to produce local language policies. In other words, promote collaborative microplanning that reduce the distance between central policy and local practices.

\section{Conclusion}

Micro-planning in language policy attempts to overcome resistance to central policies.

Research in LPP has shown that language educational policies fail at the level of implementation. We suggest granting local agents (teachers, students and institutions) the hegemonic power to mediate between the different layers of language policy: creation, appropriation and implementation. In the same vein, micro-planning reduces the space between research and local practices. It is a flexible method to empower diversity and voice the margins. We have seen how classical theory is unable to meet these goals and how Ruiz orientation model and Spolsky's language management theory market themselves as catalysts for change in the $21^{\text {st }}$ century.

\section{References:}

Fishman, J. A. (1974). Advances in language planning. The Hague: Mouton.

Francis M. Hult \& D. Johnson, C. (2015). Research methods in language policy and planning. Chichester: Wiley Blackwell.

Haugen, E. (1966). Language conflict and language planning. Cambridge, MA: Harvard University Press.

Ricento, D. C. (2013). Conceptual and theoretical perspectives in Language Planning and Policy: Situating The ethnography of Language Policy. De Gruyter, 2013(219),p. 7-21.

Ricento, N. H. (1996). Unpeeling the onion: Language planning and policy and The ELT professonals. TESOL Quarterly, 30(03), p. 10-36.

Ruiz, R. (1984). Orientations in language planning. NABE Journal, 08(02), p. 15-34. DOI http://dx.doi.org/10.1080/08855072.1984.10668464

Spolsky, B. (2009). Language management. New York: Cambridge University Press.

Spolsky, B. (2018). A modified and enriched theory of language policy (and management). Language Policy, 18(n.i.), p. 323-338. DOI https://doi.org/10.1007/s10993-018-9489-z 